
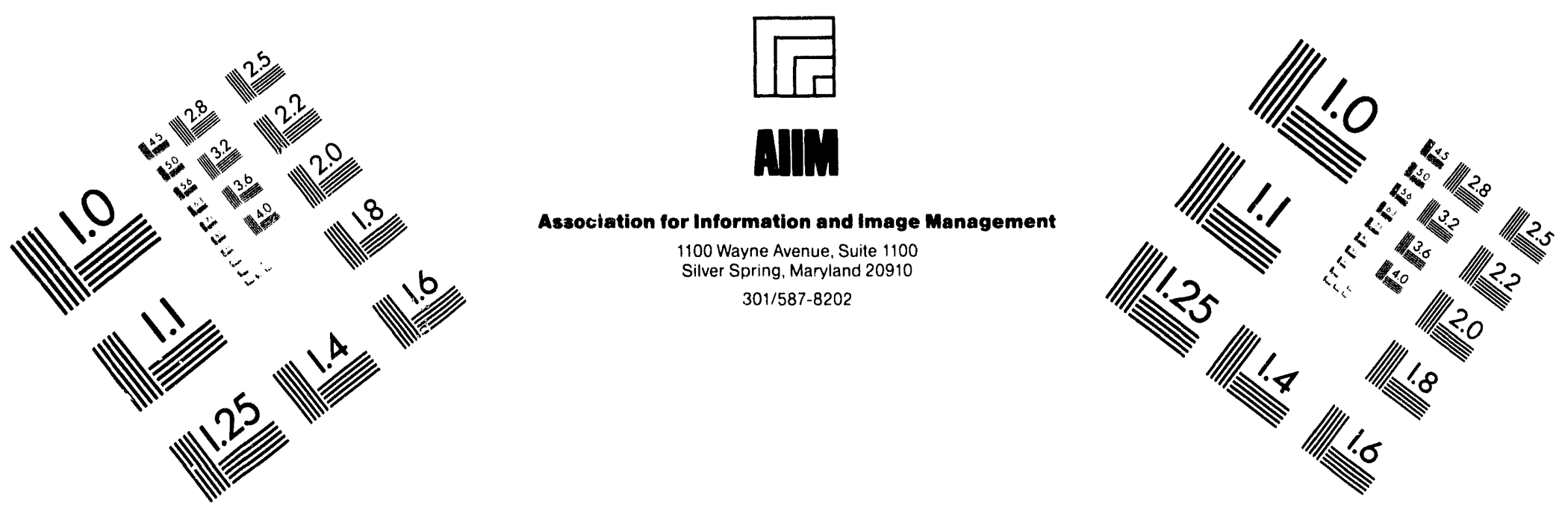

\title{
Centimeter
}

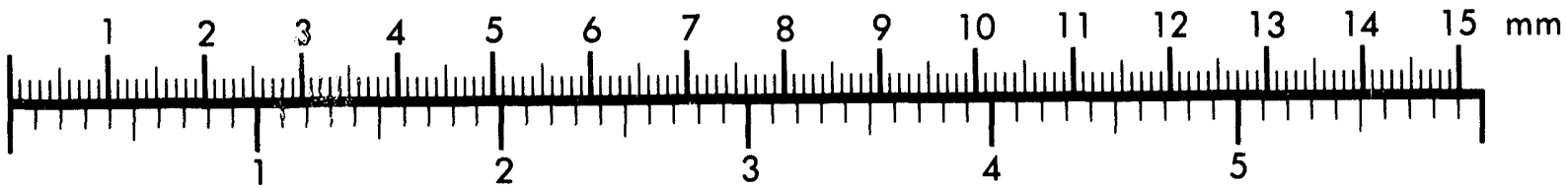

Inches
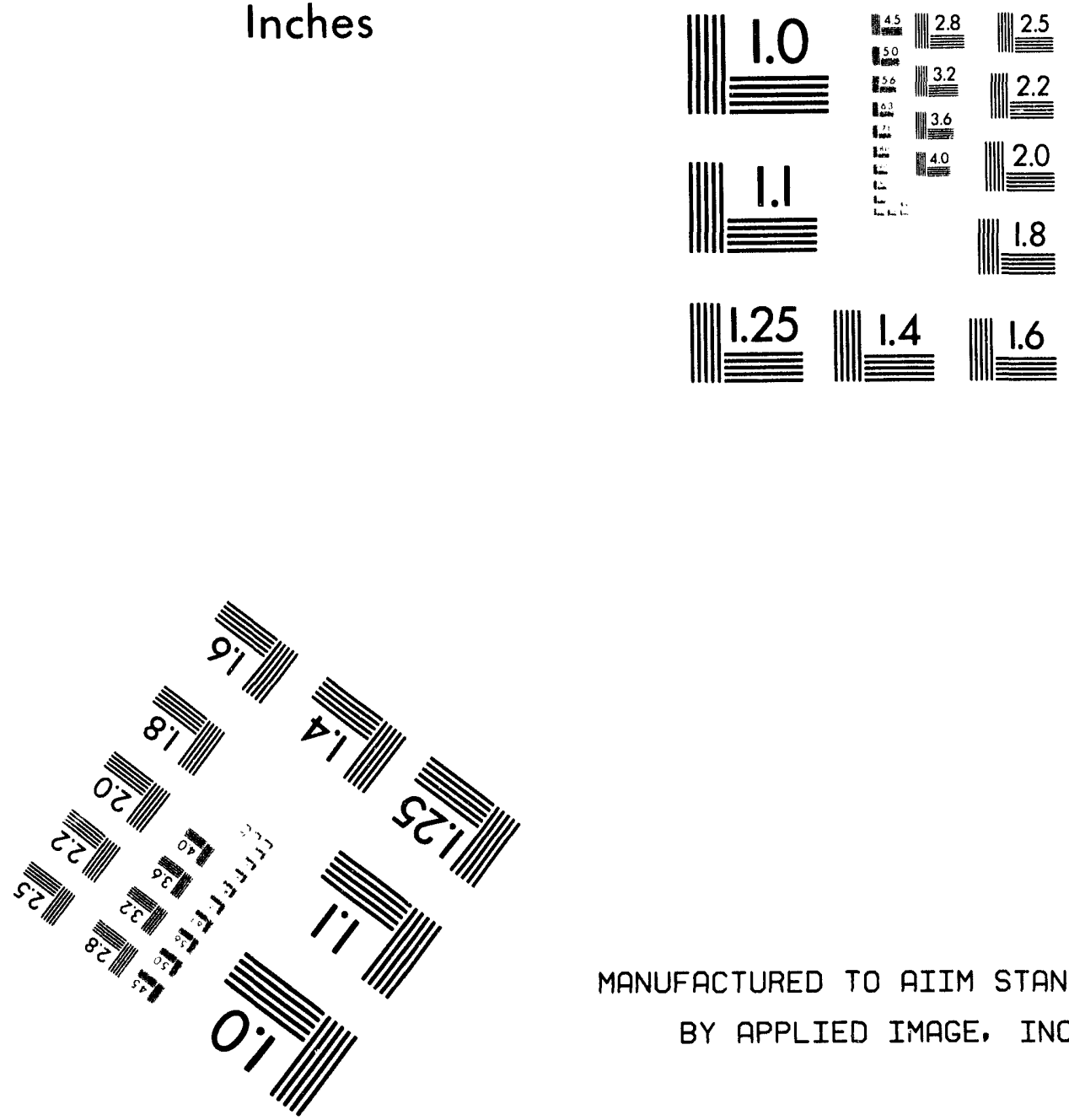

MANUFACTURED TO AIIM STANDARDS

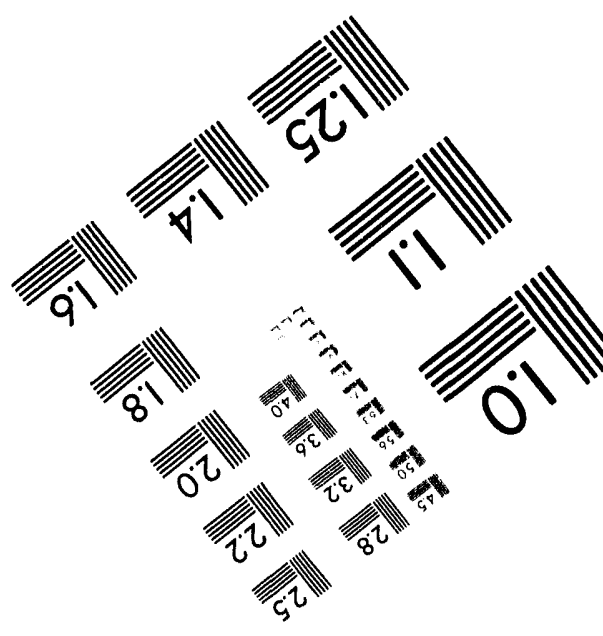



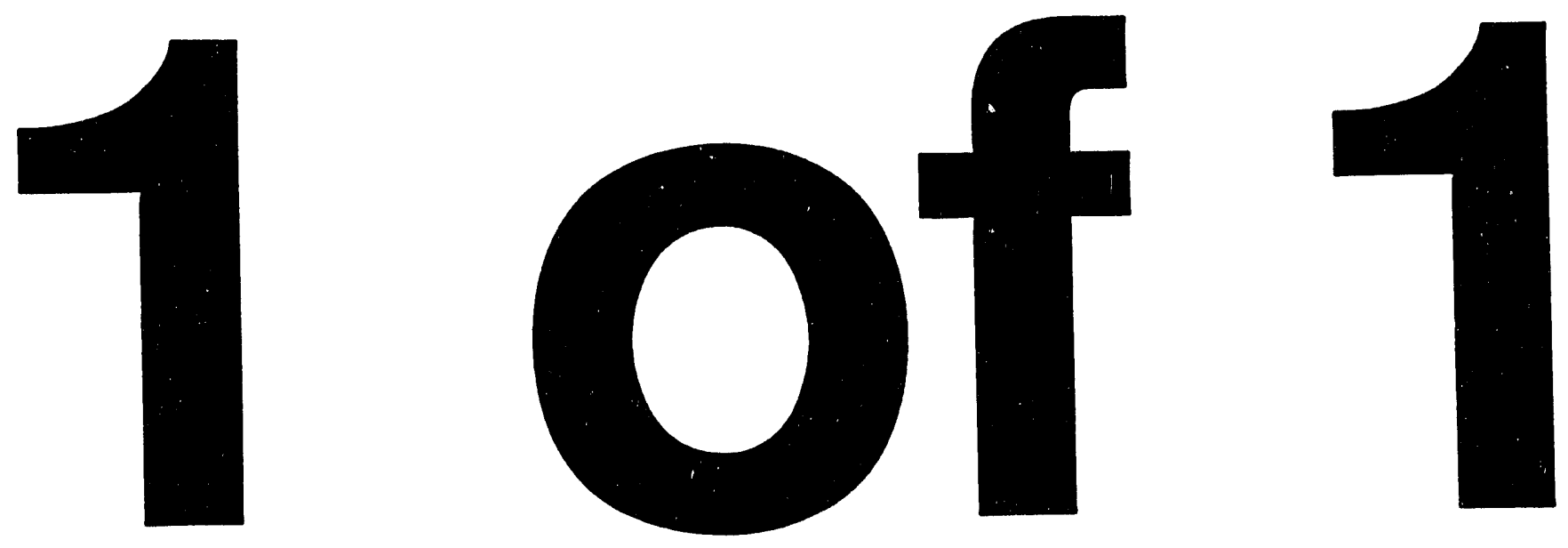
What's New in Federal Energy Management

\section{Program Overview}
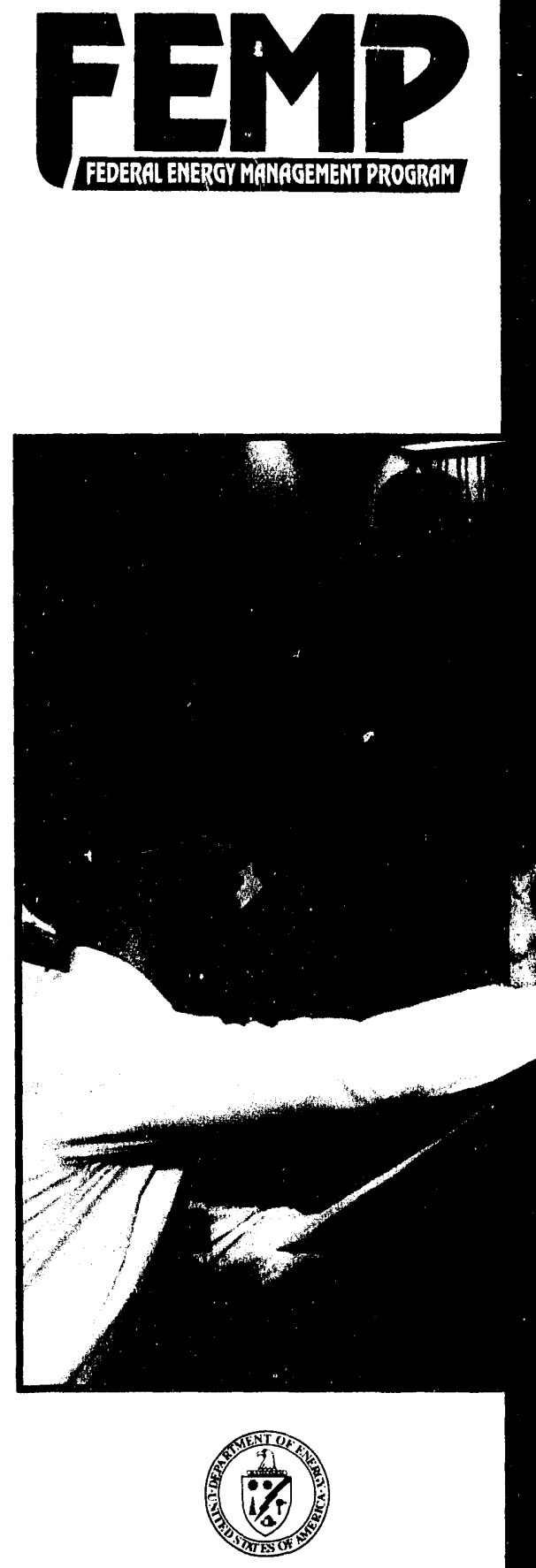

U.S. Department of Energy

\section{SAVEnergy Program}

\section{New program provides action plans for efficiency improvements}

The SAVEnergy Program provides direct assistance to federal agencies in identifying and implementing energy efficiency and water conservation measures. The Energy Policy Act of 1992 (EPACT) and Executive Order 12902 require that federal agencies reduce the energy consumed in federal buildings. The Executive Order increased the goal to a $30 \%$ reduction, compared to 1985 , by 2005 . In addition, agencies are required, to the maximum extent possible, to install all energy and water conservation measures with paybacks of less than 10 years.

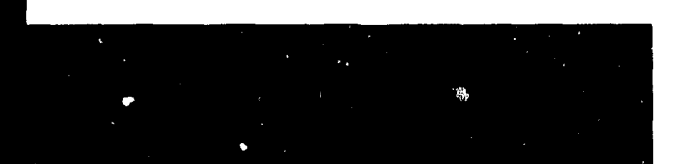


than 10-year simple payback and federal life-cycle costing

- Suggests funding sources to complete these projects. The funding sources could include agency funds, FEMP's Federal Energy Efficiency Fund, or leveraging of nonfederal financial incentives, such as utility demand-side management (DSM) programs.

- Lists other resources necessary for starting these projects to make it easier for the facility manager to start and complete a project.

\section{What does the Action Team do?}

The SAVEnergy Action Team implements the Action Plan. Team members are the energy manager and others from relevant departments-such as contracts, finance, legal, environmental, and construction. Other support comes from DOE, utilities, and contractors.

Some of the Action Team's proposed actions are to

- Review and evaluate SAVEnergy Action Plans and their implementation

- Overcome barriers to completing projects

- Facilitate energy savings performance contracts

- Evaluate agency eligibility for financing projects through the Federal Energy Efficiency Fund

- Leverage utility DSM and other funding

- Track savings and report them to the agency and DOE.

\section{What does the project data base track?}

The SAVEnergy project data base tracks energy audit results and progress on action plans to see which projects are successfully implemented. Data include cost and energy savings, emissions reduction, and job creation. Reviewing the data helps track progress in meeting EPACT goals and identifies a need for additional activities or incentives. It also provides insight into the most cost-effective opportunities for future federal energy and water conservation activities.

\section{How do federal agencies qualify?}

FEMP cannot fund every agency requesting an audit and Action Plan. FEMP wants some assurance that the agency is likely to complete its project. Therefore, FEMP asks the following questions to prescreen requesters:

- Does the facility have a project champion?

- Is there an aggressive utility DSM program?

- Does the agency have its own funds set aside for projects?

- Does the facility have transferable project opportunities?

- Is an energy service company interested in the site?

- Would this project be a likely candidate for the Federal Energy Efficiency Fund?

- Can the facility use the project as a showcase for others?

- Have site personnel attended any of the FEMP training courses?

Although FEMP does not require a "yes" answer to all of these questions, it generally favors those sites that can offer at least some of these attributes

\section{What are some current activities?}

FEMP currently has SAVEnergy audit requests for more than $100 \mathrm{mil}$ lion square feet of building space. FEMP has asked agencies to prioritize their candidate list using the prescreening questions. And it is coordinating efforts to ensure that facilities with costeffective project potential are audited.

SAVEnergy pilot programs are now operating in three DOE regions: Region 2 (New York Support Office), Region 8 (Denver Support Office), and Region 10 (Seattle Support Office). These pilot programs are exploring various approaches to the SAVEnergy process. For example, FEMP and the Indian Health Service are collaborating in the northern Great Plains states to provide audits to health facilities on Indian reservations.

Current or potential auditors in the SAVEnergy Program include companies certified by the Small Business Administration's 8(a) program, utilities, universities, DOE national laboratories, and state energy offices.

In addition, DOE issued a general solicitation for SAVEnergy auditors. Solicitations will be awarded by region under a blanket purchasing agreement in late summer 1994.

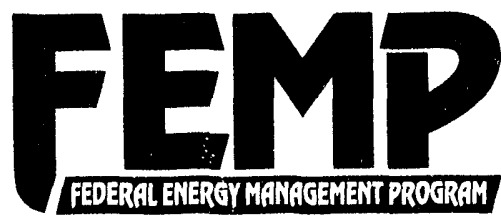

\section{For More Information}

Katherine Mayo

(202) 484-1090

FAX: (202) 484-1096

SAVEnergy Program Coordinator National Renewable Energy

Laboratory

409 12th St., SW, Suite 710

Washington, DC 20024

Mark Ginsberg, Director (202) 586-5772

Office of Federal Energy Management Programs, EE-44

U.S. Department of Energy, 5E-080

1000 Independence Ave., SW

Washington, DC 20585

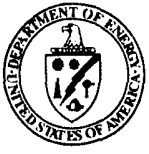

Produced for the U.S. Department of Energy (DOE) by the National Renewable Energy Laboratory, a DOE national laboratory

DOE/CH10093-333

DE94006934

September 1994

Printed with a renewable source ink on paper containing at least 50\% wastepaper including $10 \%$ postconsumer waste 

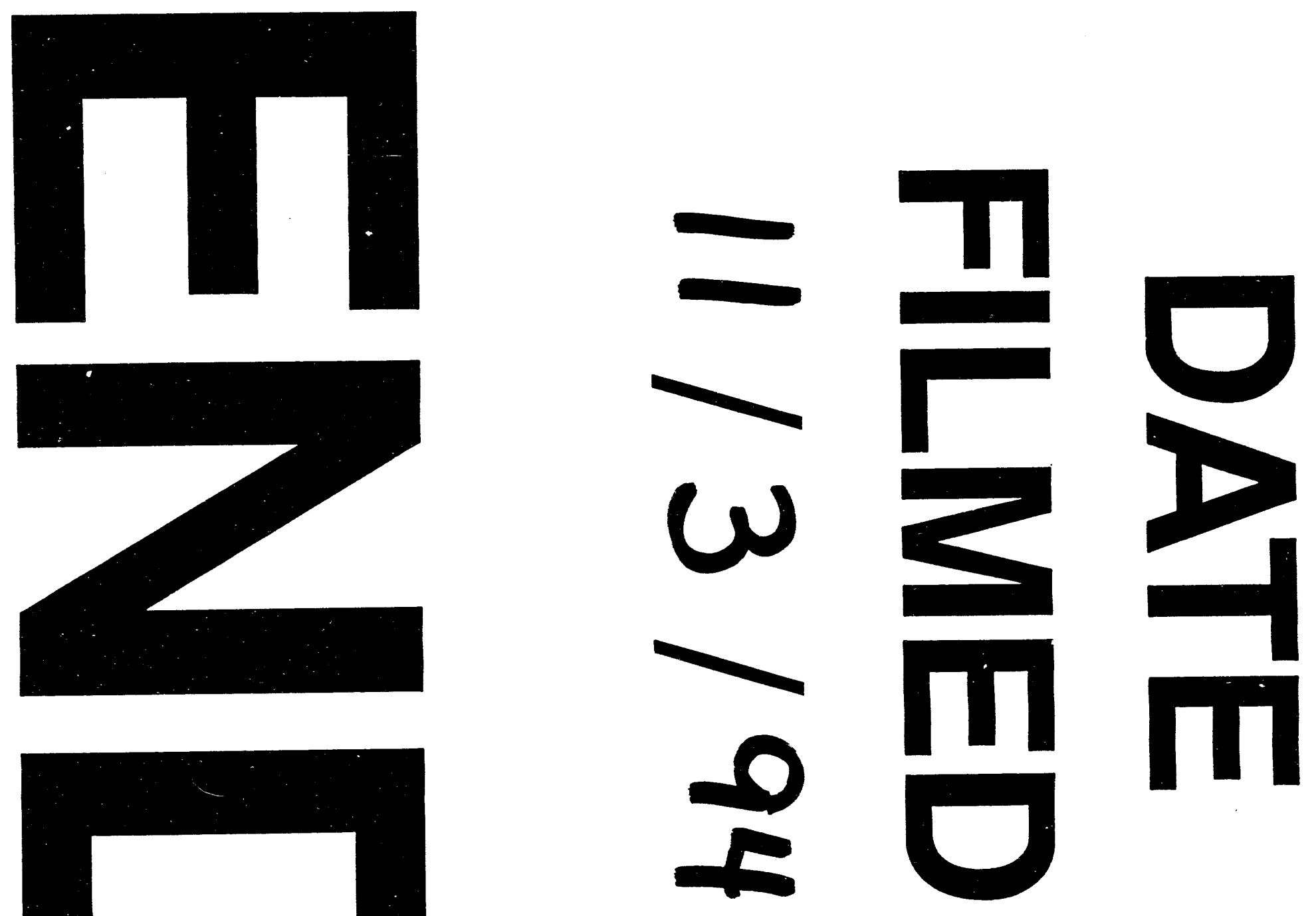
